\title{
NOISE PREDICTION OF TRACTION GEAR IN HIGH-SPEED ELECTRIC MULTIPLE UNIT
}

\author{
Tang, Z. P. ; Chen, Z. X. ; Sun, J. P.., ; Hu, Y. T. ${ }^{* *} \&$ Zhao, M. ${ }^{* * *}$ \\ *School of Information Engineering, East China Jiaotong University, Nanchang Jiangxi, 330013, China \\ ** Jiangling Holdings Ltd., Nanchang Jiangxi, 330052, China \\ **** CRRC Qishuyan Institute Co., Ltd., Changzhou Jiangsu, 213025, China \\ E-Mail: tzp@ecjtu.edu.cn, 693953364@qq.com, sunjianping@ecjtu.edu.cn $\left({ }^{\#}\right.$ Corresponding author $)$, \\ 2444495051@qq.com, zhaomin.qs@crrcgc.cc
}

\begin{abstract}
The dynamic characteristics of traction gear transmission system have great influence on the safety, comfort and reliability of EMU. Base on acoustic-structural coupled theory, the noise radiation characteristics of gear transmission system in high-speed train CRH380A are researched by finite element-boundary element method. Based on the multi-body dynamics theory, the dynamic meshing characteristics of the gear transmission system are revealed by RecurDyn. The natural frequency and the natural mode of vibrating are analysed for system by finite element method, and the vibration response curves of transmission gears under continuous working conditions are solved by modal superposition method. Furthermore, the radiated noise is predicted based on the acoustic radiation analysis model constructed by the acoustic BEM and Helmholtz boundary integral equation. The research results can provide theoretical basis for the optimization design of the low noise gear in EMU. (Received, processed and accepted by the Chinese Representative Office.)
\end{abstract}

Key Words: Traction Gear of EMU, Dynamic Characteristics, Acoustic BEM, Noise Prediction

\section{INTRODUCTION}

Traction transmission system is the core of power source for high-speed electric multiple unit (EMU), located directly below the passenger vehicle. The vibration noise derived from gear alternation meshing in the high-speed cases, not only degrades system performance, affects the comfort of passengers, but also even endangers the safety of EMU train running. That to study the dynamic mechanical characteristics and acoustic response characteristics in gear meshing process, as well as to analyse and predict the magnitude and the origin of noise is the key for improving the transmission performance of traction gear and reducing vibration and noise.

The traction gear transmission system of EMU is essentially a nonlinear multi-degree of freedom system in which time-varying parameters and transmission clearance coexist. Its structural noise is mainly dynamic response results from the joint effect of the internal excitation and external excitation in the gears meshing process. The internal excitation is the characteristic of gear transmission for distinguishing other mechanical systems, also is the source of the gear transmission system noise. By means of computer-aided modelling and finite element simulation analysis, domestic and foreign scholars have conducted extensive research on the dynamic mechanical characteristics of gear transmission. Xue et al. [1] established the spur planetary gear model by using the parametric method, simulated and analysed the gear meshing process, and obtained the contact pressure and stress in a meshing period. Kim et al. [2] proposed a new dynamic model of the planetary gear, where the pressure angles and contact ratios change with time. The dynamic responses of a planetary gear are analysed under considering time-varying pressure angles and contact ratios caused by bearing deformations. Xuan et al. [3] established the dynamic model of transmission and studied the dynamic characteristics of FT reducer at the transmission joint. Tang et al. [4] 
established finite element model of traction gear transmission system for the high-speed train CRH380A, and based on transient dynamics, analysed the distribution and variation of equivalent stress and contact pressure on the gear tooth surface. Taking the dynamic meshing force, the dynamic tooth force and the bearing force along the meshing line or away from the meshing line as measure, Ghosh and Chakraborty [5] evaluated the vibration and noise of gears under different conditions. According to the relationship between the speed and the dynamic meshing force, Cao et al. [6] proposed that the higher the rotational speed and the greater the dynamic load coefficient under the same load is, the more obvious the mesh contact impact is. As well as the maximum contact force increases sharply with the increase of rotational speed.

The noise of gear transmission is not only related to the mechanical characteristics, such as transmission error fluctuation, tooth surface stress distribution and dynamic meshing force change, but also related to the gear structural characteristics, vibration characteristics and meshing force transmission characteristics. Bahk and Parker [7] respectively took the minimized transmission error and the minimized vibration response as modification optimization objective. It is found that significant difference exits between the two optimizations. So the traditional view or hypothesis is corrected that there are strong correlation between transmission error and dynamic response. Jolivet et al. [8] studied the influence of tooth surface roughness and lubricating oil viscosity on automobile gear vibration, and the laboratory tests showed that gear noise was related to tooth surface processing technology. Divandari et al. [9] established a six-degree-of-freedom nonlinear dynamic model containing different gear errors and defects, and studied the influence of local defects and tooth shape changes on the overall dynamics of gear. The results showed that tooth shape changes and tooth shape errors had a greater impact on the vibration of gear pairs. Guo et al. [10] developed a system-level vibro-acoustic model of an actual gearbox, including gears, bearings, shafts, and housing structure, and compared the results to experiments. ĆirićKostić and Ognjanović [11] defined the mechanism of exciting and emission of transmission noise by carrying out the process of propagation of excitation energy through the structure of power transmitters and by modal testing of the housing. Wang et al. [12] calculated transmission noise of a gearbox using FEM / BEM and analysed the influences of modal shapes on the noise. The results showed that the flexural vibration of the gearbox housing has most obvious effects on the noise.

The noise analysis and prediction of gear transmission system was achieved indirectly by studying the shock vibration and dynamic load on gear teeth [13-15], however, further acoustic study is few. The main reason is that to build a noise analysis model for system is more difficult and complex [16]. It belonged to an interdisciplinary difficulty in both theory and method. In this paper, based on acoustic-structural coupled theory, by the finite-element boundary method, the dynamic characteristics and vibration response characteristics of the gear meshing has been analysed for EMU (high-speed train CRH380A) under continuous traction condition. On that basis, the acoustic response characteristics are further studied, and the noise is predicted for the gear pairs. The study lays a foundation for optimal design on noise reduction of the gear system.

\section{PARAMETERIZED MODEL}

Gear parameterization modelling has a mature design flow. In this paper, based on the constraint relationship among inner geometry parameters of gear and the involute parameter equation in Cartesian coordinate, using software PRO/E, a parametric solid model is constructed for helical gear transmission system. 
The basic geometric parameters of traction gear pair in high-speed train CRH380A are shown in Table I.

Table I: Basic geometric parameters of gear pair.

\begin{tabular}{|l|c|c|}
\hline \multicolumn{1}{|c|}{ Name } & Driving gear & Driven gear \\
\hline Teeth $z$ & 29 & 69 \\
\hline Modulus $m_{n}(\mathrm{~mm})$ & 7 & 7 \\
\hline Pressure angle $\alpha_{n}\left({ }^{\circ}\right)$ & 26 & 26 \\
\hline Helix angle $\beta\left(^{\circ}\right)$ & 20 & 20 \\
\hline Tooth face width $B$ & 70 & 70 \\
\hline The coefficient of addendum $h_{a}{ }^{*}$ & 1 & 1 \\
\hline The coefficient of tip gap $c^{*}$ & 0.25 & 0.25 \\
\hline Modification coefficient $X_{n}$ & 0 & -0.284588 \\
\hline
\end{tabular}

To define the relations of the basic parameters in table I, and to draw a series of circles and helix of the gear under the driven dimension by these relations, according to the parametric equation of the involute curve in Cartesian coordinate, the involute curve of the gear is created. The basic profile of the gear teeth can be constituted by the mirrored involute and the series of circles, and then the gear model is generated through a series of feature operations such as the swept blend, array. The noise of gear pair transmission system is mainly studied in the paper. Considering the workload of simulation calculation, to ignore some parts such as the transmission shaft, bearing and spline, the simplified gear pair model is taken as a research object (Fig. 1).

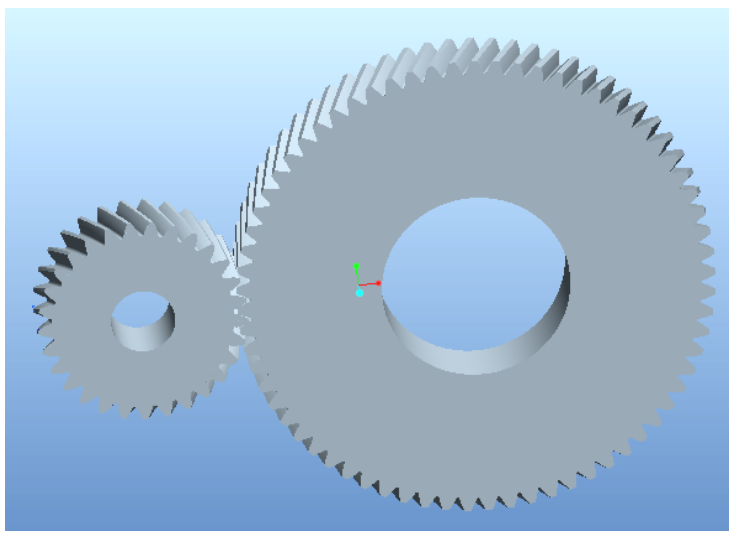

Figure 1: Simplified model of gear transmission system.

\section{DYNAMIC CHARACTERISTICS ANALYSIS}

The dynamic characteristics of gear transmission system include dynamic meshing characteristics, modal characteristics and vibration response characteristics. By analysing and solving the dynamic characteristics of gear pair, the accurate sound source and acoustic boundary conditions can be provided for the acoustic radiation study.

\subsection{Kinetics equation of gear pair}

The meshing impact force (dynamic excitation force) is main inducement of the gear vibration noise. The meshing force characteristics are analysed and solved by the multi-body dynamics analysis software RecurDyn.

According to Newton's law, the differential equations of motion for the gear pair can be expressed as: 


$$
\begin{aligned}
& I_{p} a_{p}+R_{p} c_{m}\left(R_{p} v_{p}-R_{g} v_{g}-e(t)\right)+R_{p} k(t) f\left(R_{p} s_{p}-R_{g} s_{g}-e(t)\right)=T_{p} \\
& I_{g} a_{g}+R_{g} c_{m}\left(R_{p} v_{p}-R_{g} v_{g}-e(t)\right)+R_{g} k(t) f\left(R_{p} s_{p}-R_{g} s_{g}-e(t)\right)=-T_{g}
\end{aligned}
$$

In the equation, $s_{i}(i=p, g), v_{i}(i=p, g)$ and $a_{i}(i=p, g)$ respectively are the vibration displacement, speed and acceleration of the driving gear or driven gear. $R_{i}(i=p, g)$ and $I_{i}(i=p, g)$ respectively are the base circle radius and rotary inertia of the driving or driven gear. $k(t)$ is gear pair mesh synthesizing stiffness. $e(t)$ is gear pair mesh synthesis error. $C_{m}$ is gear pair mesh damping. $T_{i}(i=p, g)$ is torque of the driving or driven gear.

Due to the dynamic meshing force mainly results from the mesh stiffness of gear, according to the Eq. (1), the dynamic meshing force can be expressed as:

$$
F(t)=k(t) f\left(R_{p} s_{p}-R_{g} s_{g}-e(t)\right)=\left(T_{p}-I_{p} a_{p}+R_{p} c_{m}\left(R_{p} v_{p}-R_{g} v_{g}-e(t)\right)\right) / R_{p}
$$

\subsection{Simulation of gear dynamic meshing}

The built model of gear pair in PRO/E is imported into software RecurDyn and the dynamic meshing force of gear pair can be solved. The main steps are as follows:

(1) To define transmission mode. The imported model mode is defined as gear transmission, and the driving gear and driven gear are assigned.

(2) To define material properties. The density, elastic modulus, Poisson's ratio and other material properties are respectively given to the gears, as shown in Table II.

Table II: Material properties of gear pair.

\begin{tabular}{|l|c|c|}
\hline \multicolumn{1}{|c|}{ Material properties } & Driving gear & Driven gear \\
\hline Elastic modulus $E(\mathrm{MPa})$ & $2.06 \times 10^{11}$ & $2 \times 10^{11}$ \\
\hline Poisson's ratio $\mu$ & 0.31 & 0.29 \\
\hline Density $\rho\left(\mathrm{kg} / \mathrm{m}^{3}\right)$ & 850 & 7800 \\
\hline
\end{tabular}

(3) To define boundary conditions. To set the constraint conditions, speed and load for the gear transmission system, and it shall conform as closely as possible to reality. The driving gear and driven gear is constrained as only rotation. The speed and torque are respectively $841.5 \mathrm{Nm}$ and $434 \mathrm{rad} / \mathrm{s}$ for traction gear pair of high-speed train CRH380A under the continuous working condition.

(4) To simulate and solve. The solution mode is selected as dynamics. The time domain of the solution is set as $0-5 \mathrm{~s}$, the time domain step is set as $0.0001 \mathrm{~s}$, and the frequency domain is set as $0-3500 \mathrm{~Hz}$. According to Eq. (2), the dynamic meshing force is solved by the nonlinear finite element simulation analysis.

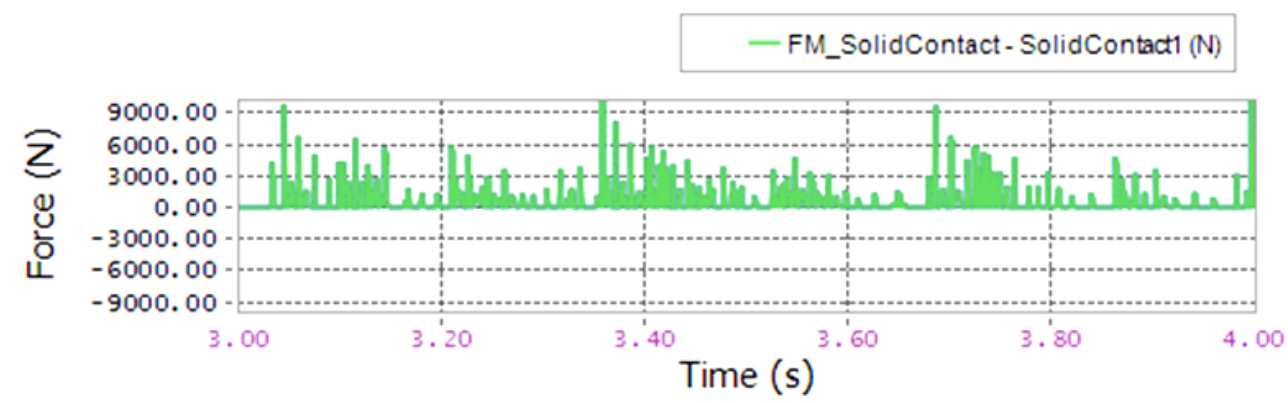

Figure 2: Time domain diagram of meshing force.

Considering the steady-state process of the system, the time range of the time domain diagram is selected as 3-4 s (Fig. 2). The frequency domain diagram of meshing force is plotted by FFT (fast Fourier transform) (Fig. 3). 


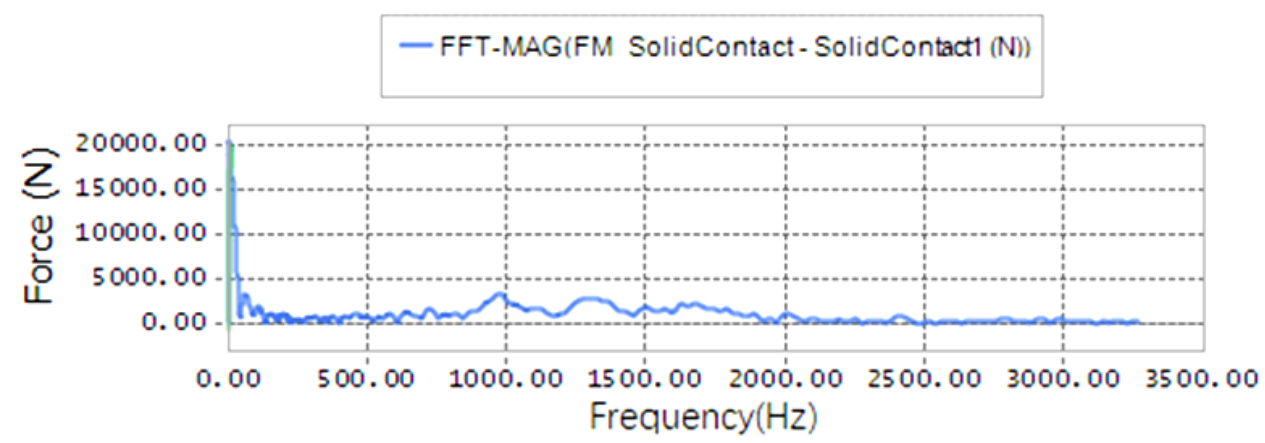

Figure 3: Frequency domain diagram of meshing force.

It can be seen from Figs. 2 and 3, the overall trend of the meshing force in each period is stable and presents a periodic variation law although the meshing force fluctuates with time. In addition, the analysis and solution can provide the data for the analysis of vibration response characteristics and noise radiation characteristics of gear transmission system.

\subsection{Modal analysis}

The vibration characteristics of the mechanism caused by external force have relation not only to external excitation, but also to its natural frequency and natural mode of vibrating. By the modal analysis, the any ordered natural frequencies and modal characteristics of the transmission gear pair in a certain frequency range can be solved. On this basis, the vibration response of the gear pair under various excitations can be predicted in a certain frequency range.

According to the kinetics equation of undamped free vibration system in modal theory, by Fourier transformation, it can be obtained as follows:

$$
[K]\left\{\Phi_{i}\right\}=\omega_{i}^{2}[M]\left\{\Phi_{i}\right\}
$$

In Eq. (3), $M$ is systematic mass matrix, $K$ is stiffness matrix, $\Phi$ is time-invariant eigenvector. The eigenvalue $\omega_{i}$ is systematic natural frequency.

The modal analysis can be realized by the workbench module in ANSYS. The specific steps are as follows:

(1) To construct 3D models and define material properties. The operation is the same as that in section 3.2.

(2) To generate mesh. The smaller the mesh division is, the more accurate the solution is. However, the corresponding workloads will be increased. Therefore, it is necessary to define reasonably edge length for mesh under the premise in accuracy.

(3) To define boundary conditions. To set the boundary constraint conditions of the gear transmission system, and it shall conform as closely as possible to reality.

(4) To simulate and solve. To select the modal order to solve, the first 6 order modes of gear pair are set in this paper.

The finite element structures were solved by Eq. (3), and the results are shown in Table III. The first vibrating model is shown in Fig. 4, and the others are omitted.

Table III: The first six order natural frequency of gear pair.

\begin{tabular}{|c|c|}
\hline Order & Frequency $(\mathrm{Hz})$ \\
\hline 1 & 507.34 \\
\hline 2 & 769.1 \\
\hline 3 & 882.65 \\
\hline 4 & 1457.6 \\
\hline 5 & 2186.7 \\
\hline 6 & 2603 \\
\hline
\end{tabular}




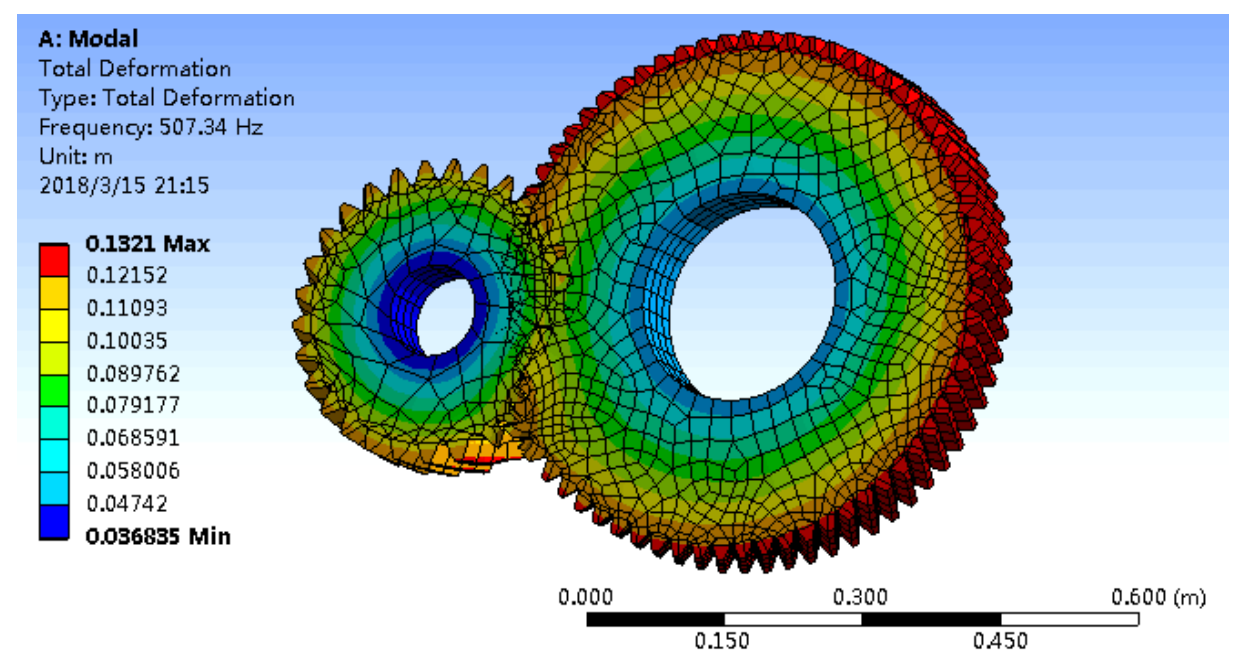

Figure 4: The first order natural mode of vibration of gear pair.

\subsection{Dynamic harmonic response analysis}

Because the fluctuating law of the dynamic meshing force of the gear pair approximates to a sinusoid function, the harmonic response and the vibration response of the gear transmission system under the meshing shock excitation should be analysed. The harmonic response analysis includes vibration displacement, vibration velocity and vibration acceleration. In the analysis, the peak value and the corresponding frequency should be emphatically observed as to avoid fatigue and resonance in gear transmission system design. The forced vibration equation of undamped system is:

$$
[M]\{a\}+[K]\{s\}=\{F\}
$$

In the equation, $s$ is vibration displacement, $a$ is vibration acceleration.

The excitation load of harmonic response can be expressed as:

$$
F_{i}=F_{i \max } \sin \left(\omega t+\theta_{i}\right)
$$

In Eq. (5), $F_{i \max }$ is load amplitude, $\omega$ is load frequency, $\theta$ is load phase angle.

By using workbench, the structural harmonic response can be analysed. The main steps are as follows:

(1) To import model and define material.

(2) To define the contact of gear pair.

(3) To generate mesh. The results of harmonic response analysis will be used for simulation on the noise radiation, and the volume meshes will also be used to extract and generate acoustic surface mesh. The acoustic radiation simulation requires more accurate results. So the size of the acoustic mesh will be limited. The maximum edge length can't exceed 1/6 of the corresponding acoustic wavelength in the maximum scanning frequency [17]. In the harmonic response analysis, the scanning frequency range $f_{a}$ is $100-2400 \mathrm{~Hz}$, the acoustic velocity $v_{a}$ equals $340 \mathrm{~m} / \mathrm{s}$, so the corresponding acoustic wavelength in the maximum scanning frequency is:

$$
\lambda_{\min }=\frac{v_{a}}{f_{a}}=141.67 \mathrm{~mm}
$$

Then the maximum edge length of mesh element is:

$$
l_{\max } \leq \frac{1}{6} \lambda_{\min }=23.61 \mathrm{~mm}
$$

So, the edge length of mesh element is set to $16-20 \mathrm{~mm}$. By Workbench, as the block of model change sharply, the mesh block is finer, and as the block change smoothly, the mesh block is bulkier. 
(4) To load and solve. Type of analysis is assigned as harmonic response. The specified analysis options include the output form and the formation of the mass matrix for the solution. According to the results of the dynamic meshing force in the previous section, the amplitude, phase angle and frequency range of the load are assigned.

(5) To simulate and analyse. According to Eq. (4), the vibration response characteristics are calculated and the frequency response curve is output (Fig. 5).

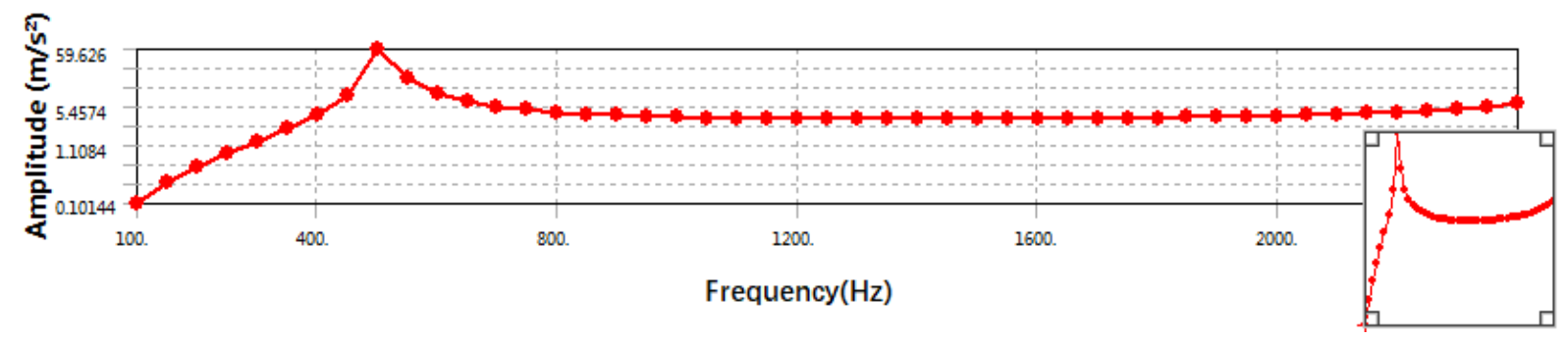

Figure 5: Frequency response curve of gear pair.

According to Fig. 5, the frequency response curve has a peak at frequency $500 \mathrm{~Hz}$, and to compare with the modal analysis results in the section 3.3, the peak-owes the $500 \mathrm{~Hz}$ is close to the first order natural frequency 507.34 of gear pairs. However, there is no significant peak near the subsequent order natural frequencies; it shows that the generated vibration of gear transmission concentrated in the low frequency band. It is completely consistent with the actual situation, in the meantime, the reliability of the model and method is verified.

\section{TRANSMISSION NOISE ANALYSIS}

The above dynamic characteristics analysis can provide boundary conditions for acoustic noise analysis of gear transmission system.

\subsection{Numerical computation method}

To solving the acoustic radiation problem in unbounded sound field, if the whole model entity is meshed by the finite element method, the computational complexity is often too high to calculate. However, by the boundary element method based on Helmholtz boundary integral equation, the acoustic radiation calculation can be accomplished by extracting the surface mesh of the structure [18]. The expression is as follows:

$$
p=\left[A_{v}(w)\right]^{T} v_{n}(w)
$$

In Eq. (8), $p$ is sound pressure, $A_{v}(w)$ is acoustic transfer vector, $v_{n}(w)$ is the normal velocity of vibration on structural surface unit.

Then, the normal velocity $v_{n}$ and sound pressure $p$ at any point with a distance of $r$ to the origin in the acoustic radiation field of gear transmission system are satisfied as:

$$
\begin{aligned}
& p\left(r_{a}\right)=\sum_{i=1}^{n_{e}} N_{i}^{e}\left(r_{a}\right) \cdot a_{p i}, r_{a} \in \Omega_{a e} \\
& v_{n}\left(r_{a}\right)=\sum_{i=1}^{n_{e}} N_{i}^{e}\left(r_{a}\right) \cdot a_{v i}, r_{a} \in \Omega_{a e}
\end{aligned}
$$

In Eqs. (9) and (10), $n_{e}$ is the number of nodes on the $\Omega_{a e}$ unit, $a_{p i}$ is sound pressure on the boundary element nodes, $a_{v i}$ is normal velocity on the unit nodes, $N_{i}^{e}$ is shape function of unit.

The range of human hearing is very wide, so it is inconvenient to directly reflect the strength of sound by using the sound intensity or sound pressure. For comparison purposes, sound pressure is measured by logarithmic scale. Acoustic pressure level is defined as 20 
times the logarithm of the ratio of the effective sound pressure to the reference acoustic pressure, i.e.,

$$
L_{p}=20 \lg \frac{p_{\varepsilon}}{p_{r}}
$$

In Eq. (11), $p_{\varepsilon}$ is the measured sound pressure, $p_{r}$ is the reference acoustic pressure, and usually $p_{r}=2 \times 10^{-5} \mathrm{~Pa}$, it is the lowest sound pressure value can be perceived $1 \mathrm{kHz}$ sound in air by human ears.

Acoustic pressure level is nondimensional number, and it is generally in decibels $(\mathrm{dB})$ for easy use and good understanding.

\subsection{Noise analysis based on boundary element method}

The obtained results of the vibration response from the analysis in section 3 are imported into the noise vibration analysis software LMS, and the noise can be simulated and predicted. The main steps are shown as follows:

(1) To import related data. The material properties and mesh models of the gear pair are imported. The finite element mesh model can be directly used as the structural mesh of the acoustic boundary element model, and the acoustic boundary element surface mesh can be obtained by extracting the envelope mesh of the gear surface. Additional, the previously obtained *.rst file from Workbench's vibration response results can be imported into the acoustic boundary element module of LMS's Virtual.Lab.

(2) To define the material properties and create sound field mesh. The sound field medium is defined as the air fluid property, and the action of the field point is similar to the acoustic sensor, where it needs to calculate the noise level [19]. The ISO standard spherical mesh is created and centres on gear pairs (Fig. 6).

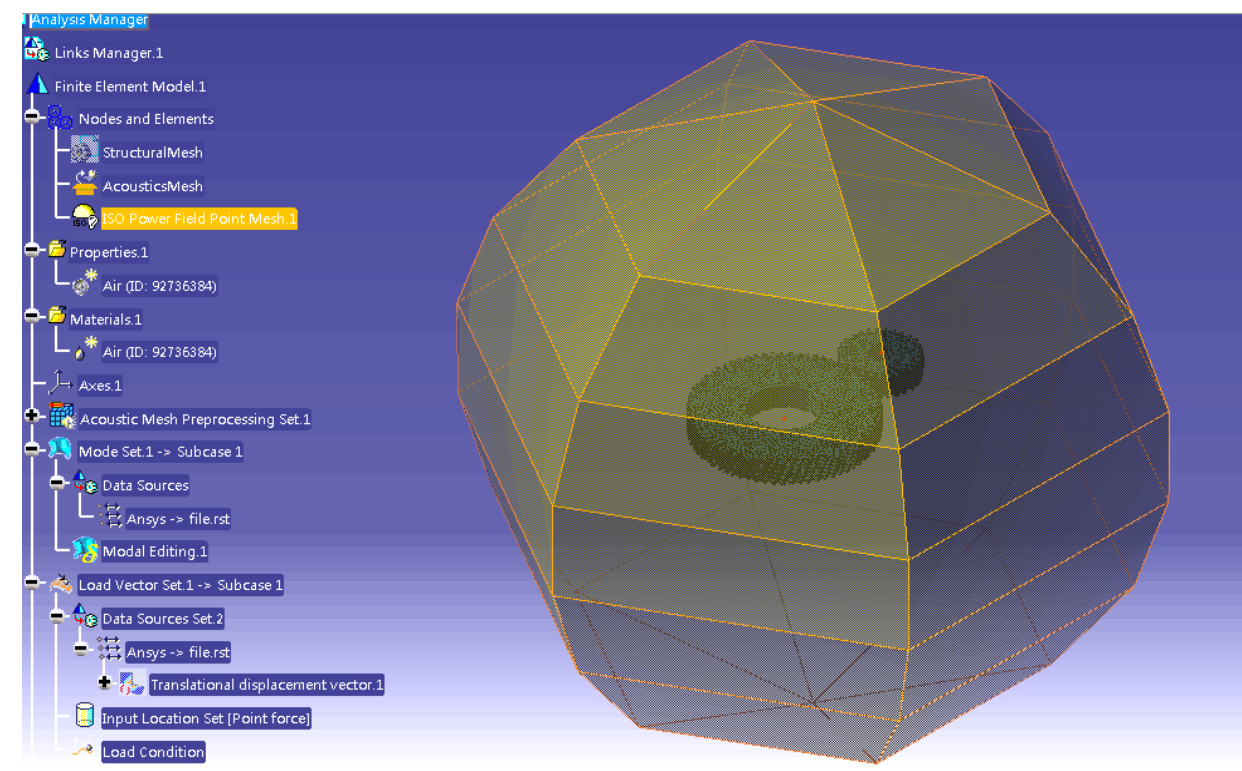

Figure 6: The sound field mesh.

(3) To transfer vibration response data. In Virtual.Lab, firstly, the data from the harmonic response analysis must be transferred to the acoustic mesh by interpolation, then the vibration response of the acoustic mesh can be excited. The volume mesh of the model has much larger quantity than that of the acoustic boundary element mesh, so it is necessary to map some elements on the volume mesh to the acoustic mesh node.

In this paper, 4 nodes interpolation is used, that is, the vibration response data of the 4 finite elements are mapped to the node $E$ on the acoustic boundary element. Supposing that 
the distances between $E$ and 4 points respectively are $d_{1}, d_{2}, d_{3}, d_{4}$, and corresponding vibration velocities are respectively, the mapped velocity on $E$ is:

$$
v_{E}=\frac{\frac{v_{1}}{d_{1}}+\frac{v_{2}}{d_{2}}+\frac{v_{3}}{d_{3}}+\frac{v_{4}}{d_{4}}}{\frac{1}{d_{1}}+\frac{1}{d_{2}}+\frac{1}{d_{3}}+\frac{1}{d_{4}}}
$$

(4) To simulate and analyse. In Virtual.Lab, acoustic boundary element method is chosen. According to the Eq. (9), the acoustic pressure level nephogram of the radiation noise for gear transmission in the ISO standard spherical sound field is obtained as Fig. 7.

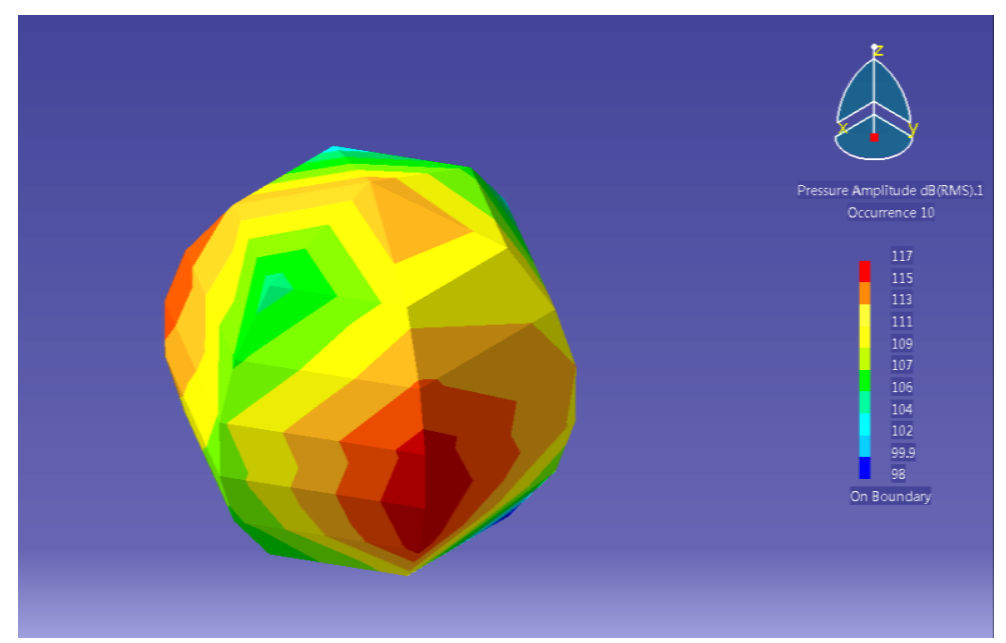

Figure 7: Acoustic pressure level nephogram.

The distance is about $1 \mathrm{~m}$ from each point to the centre of the gear pair on the ISO spherical acoustic field. Taking the positions of passengers are right above the gear pair into consideration, in the sound field, as marked in Fig. 8, the four appropriate points is selected. To check the sound pressure level at those points, and the corresponding sound pressure level curves are plotted (Fig. 9).

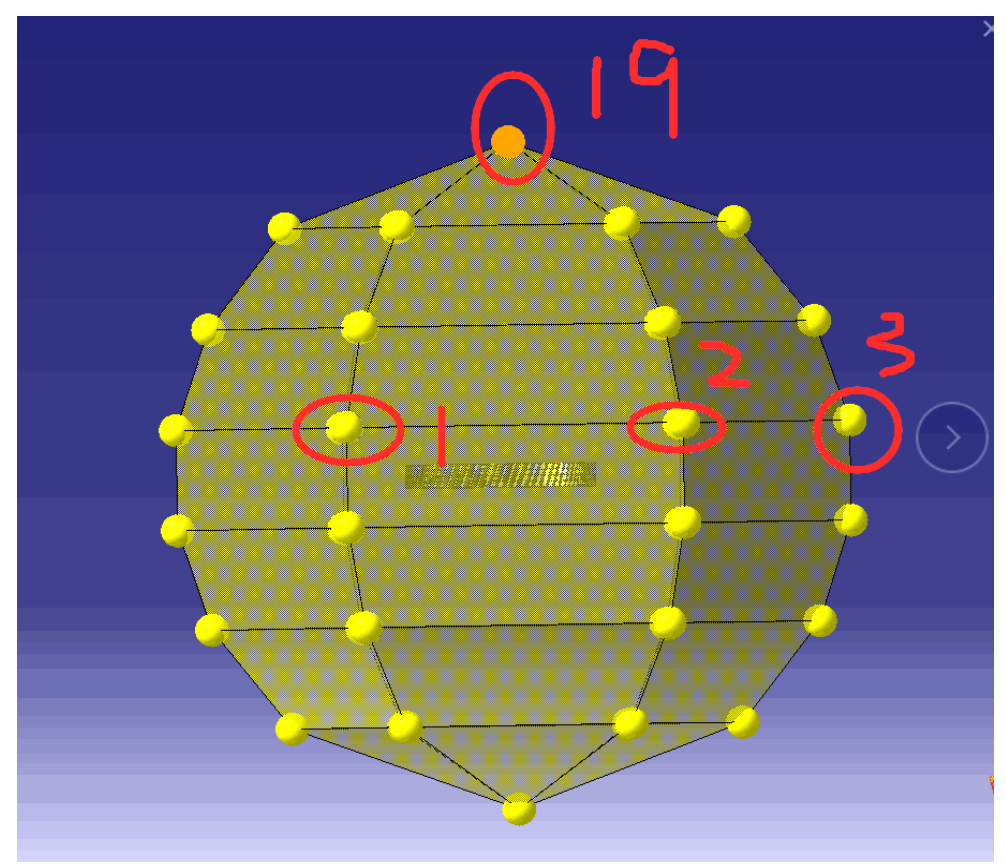

Figure 8: Schematic diagram of selected points. 


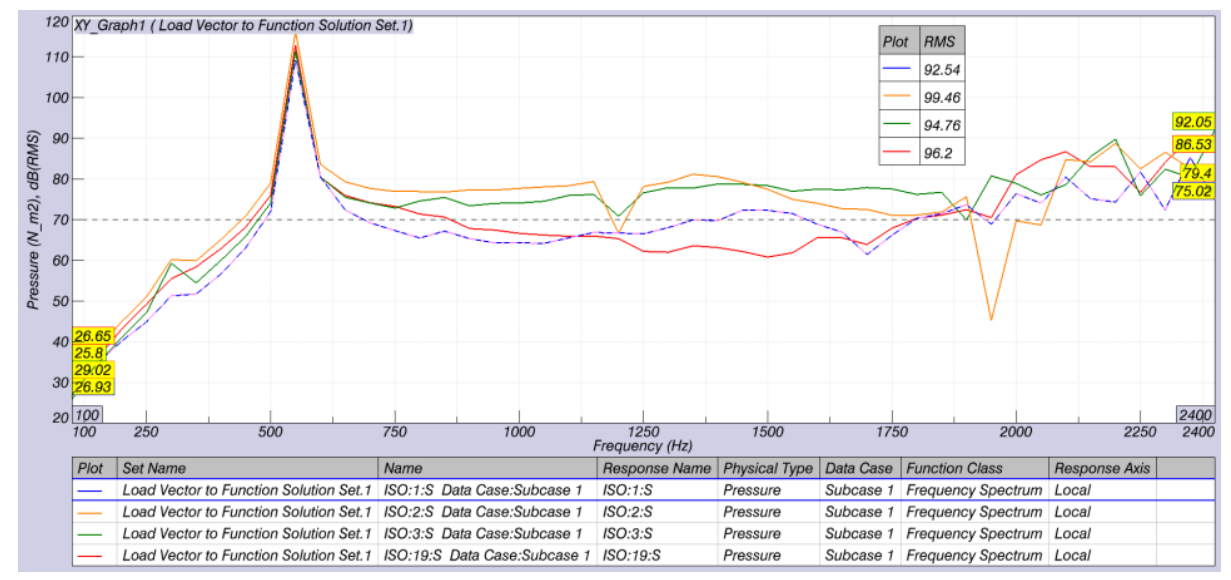

Figure 9: Acoustic pressure level curve of points.

\section{RESULTS}

From the Fig. 9, the RMS value represents the root mean square of the acoustic pressure level curve at the four points in the whole scanning frequency, that is, the sound is in the range of the human ear at the four points. It can be seen that the detecting sound has a difference in orientation, so the level of radiated noise will not be judged by the noise at a specific point.

In the paper, the sound power level will be solved for reflecting the radiated energy of the sound source per unit time. Its expression is shown as follows:

$$
W=\zeta c_{0} S
$$

In Eq. (13), $c_{0}$ is the speed of sound propagation, $S$ is the area of acoustic diffusion direction, $\zeta$ is sound energy density, and can be calculated as Eq. (14).

$$
\zeta=\frac{E}{V_{0}}=\frac{1}{2} \rho_{0}\left(v^{2}+\frac{1}{2 \rho_{0} c_{0}^{2}} p^{2}\right)
$$

Also for comparative purposes, the acoustic power level is defined as 10 times the logarithm of the ratio of the acoustic power to the baseline value, i.e.,

$$
L_{\omega}=10 \lg \frac{W}{W_{0}}
$$

In Eq. (15), the baseline value of acoustical power $W_{0}$ is $10^{-12} \mathrm{~W}$.

Through the acoustic pressure level curve (Fig. 9), according to the Eqs. (13) to (15), the sound power level curve and its root mean square $(R M S)$ can be obtained (as Fig. 10). From Fig. 10, it can be seen that the corresponding $R M S$ in the whole scanning frequency band is $114.44 \mathrm{~dB}$.

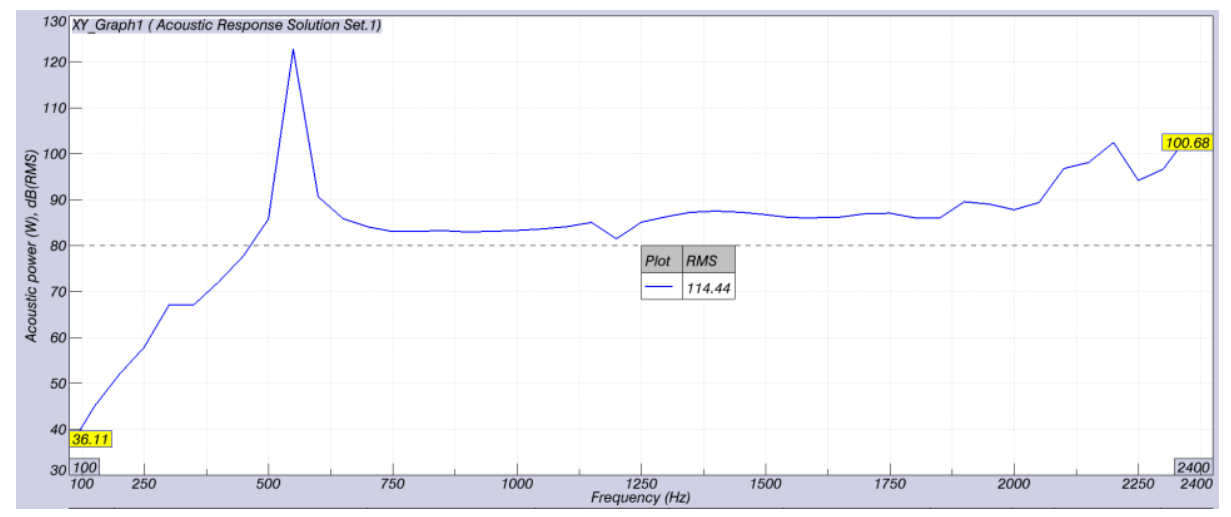

Figure 10: Sound power curve. 


\section{CONCLUSIONS}

Through the simulation analysis on the dynamic mechanical properties and acoustic response characteristics of the traction gear transmission system in high-speed train CRH380A, by using of the finite element-boundary element method, the noise of the gear transmission system is predicted which can provide reference for the optimization design and the modification design of low noise gears in high-speed EMUs. The main conclusions are shown as follows:

(1) Based on the parametric model of traction gear transmission system in high-speed EMU, the dynamic characteristics are analysed, including dynamic meshing force, natural vibration characteristics and dynamic vibration response. There is a close connection among them. The analysis of dynamic meshing force reveals excitation sources for the vibration response. By modal analysis, the natural frequencies and corresponding vibration modes can be obtained, to provide a theoretical basis for judging the harmonic response analysis. The research results show that the generated vibration is mainly concentrated in the middle and low frequency band in the running process of the gears, and the peak value occurs around $500 \mathrm{~Hz}$, which is just corresponding to the first order natural frequency.

(2) The vibration characteristic curve from harmonic response analysis, can establish boundary conditions for solving the noise response in boundary element method. Using two indexes of acoustic pressure level and sound power level respectively, and based on acoustic simulation software Virtual.Lab, the noise of gear transmission system is predicted. The $R M S$ of sound power level of the traction gear in the whole scanning frequency band is $114.44 \mathrm{~dB}$.

(3) In multiple stages, such as system modelling, dynamic analysis, vibration response analysis and so on, for taking advantage of various simulation soft wares fully, it is necessary to reasonably deal with the model compatibility and data transmission. This article provides a new idea and method for noise prediction on the coupled acoustic-structure system.

\section{ACKNOWLEDGEMENT}

This project is supported by the National Natural Science Foundation of China (51765015) and supported by the Natural Science Foundation Project of Jiangxi Province (20171BAB206027).

\section{REFERENCES}

[1] Xue, S.; Entwistle, R.; Mazhar, I.; Haward, I. (2016). The spur planetary gear torsional stiffness and its crack sensitivity under quasi-static conditions, Engineering Failure Analysis, Vol. 63, 106-120, doi:10.1016/j.engfailanal.2016.02.019

[2] Kim, W.; Lee, J. Y.; Chung, J. (2012). Dynamic analysis for a planetary gear with time-varying pressure angles and contact ratios, Journal of Sound and Vibration, Vol. 331, No. 4, 883-901, doi:10.1016/j.jsv.2011.10.007

[3] Xuan, L.; Xie, C.; Guan, T.; Lei, L.; Jiang, H. (2019). Research on dynamic modeling and simulation verification of a new type of FT pin-cycloid transmission, Proceedings of the Institution of Mechanical Engineers, Part C: Journal of Mechanical Engineering Science, Vol. 233, No. 17, 6276-6288, doi:10.1177/0954406219861999

[4] Tang, Z. P.; Sun, J. P.; Yan, L.; Lou, F. (2017). Dynamic contact analysis and tooth modification design for EMU traction gear, International Journal of Simulation Modelling, Vol. 16, No. 4, 742-753, doi:10.2507/IJSIMM16(4)CO20

[5] Ghosh, S. S.; Chakraborty, G. (2016). On optimal tooth profile modification for reduction of vibration and noise in spur gear pairs, Mechanism and Machine Theory, Vol. 105, 145-163, doi:10.1016/j.mechmachtheory.2016.06.008

[6] Cao, M.; Tang, J.; Lei, D. (2015). Finite element simulation analysis for dynamic meshing force of straight tooth face gear, Journal of Mechanical Transmission, Vol. 2015, No. 4, 96-101, doi:10.16578/j.issn.1004.2539.2015.04.023 
[7] Bahk, C.-J.; Parker, R. G. (2013). Analytical investigation of tooth profile modification effects on planetary gear dynamics, Mechanism and Machine Theory, Vol. 70, 298-319, doi:10.1016/ j.mechmachtheory.2013.07.018

[8] Jolivet, S.; Mezghani, S.; Isselin, J.; El Mansori, M. (2016). Experimental and numerical study of tooth finishing processes contribution to gear noise, Tribology International, Vol. 102, 436-443, doi:10.1016/j.triboint.2016.06.005

[9] Divandari, M.; Aghdam, B. H.; Barzamini, R. (2012). Tooth profile modification and its effect on spur gear pair vibration in presence of localized tooth defect, Journal of Mechanics, Vol. 28, No. 2, 373-381, doi:10.1017/jmech.2012.42

[10] Guo, Y.; Eritenel, T.; Ericson, T. M.; Parker, R. G. (2014). Vibro-acoustic propagation of gear dynamics in a gear-bearing-housing system, Journal of Sound and Vibration, Vol. 333, No. 22, 5762-5785, doi:10.1016/j.jsv.2014.05.055

[11] Ćirić-Kostić, S.; Ognjanović, M. (2007). The noise structure of gear transmission units and the role of gearbox walls, FME Transactions, Vol. 35, No. 2, 105-112

[12] Wang, J.-P.; Chang, S.; Liu, G.; Wu, L.-Y.; Chang, L.-H. (2015). Gearbox noise reduction based on modal acoustic contributions, Journal of Vibration and Shock, Vol. 34, No. 17, 50-57, doi:10.13465/j.cnki.jvs.2015.17.009

[13] Yan, Y. (2020). Load characteristic analysis and fatigue reliability prediction of wind turbine gear transmission system, International Journal of Fatigue, Vol. 130, paper 105259, doi:10.1016/j.ijfatigue.2019.105259

[14] Carbonelli, A.; Rigaud, E.; Perret-Liaudet, J. (2016). Vibro-acoustic analysis of geared systemspredicting and controlling the whining noise, Fuchs, A.; Nijman, E.; Priebsch, H. H. (Eds.), Automotive NVH Technology, Springer, Cham, 63-79, doi:10.1007/978-3-319-24055-8_5

[15] Zeng, Q. L.; Wang, K.; Wang, L. R.; Zhang, X. (2017). Accurate modelling and transient meshing analysis of involute spur gear base based on the principle of gear shaping, International Journal of Simulation Modelling, Vol. 16, No. 2, 322-333, doi:10.2507/IJSIMM16(2)CO7

[16] He, Z. Y.; Lin, T. J.; Liu, W.; Liu, B. (2014). Acoustic optimization design method of gear system, Advanced Materials Research, Vol. 1016, 256-260, doi:10.4028/ www.scientific.net/amr.1016.256

[17] Ramadani, R.; Belsak, A.; Kegl, M.; Predan, J.; Pehan, S. (2018). Topology optimization based design of lightweight and low vibration gear bodies, International Journal of Simulation Modelling, Vol. 17, No. 1, 92-104, doi:10.2507/IJSIMM17(1)419

[18] Wamsler, M. (2009). The role of actual modal-contributions versus frequency to optimize the structure, Engineering with Computers, Vol. 25, No. 2, 131-138, doi:10.1007/s00366-008-0100-7

[19] Wang, Y.; Jin, M.; Wang, Y.; Zhou, B.; Pan, J. (2019). Measurement and analysis of sound radiation from coherently vibrating shunt reactors, Journal of Mechanical Science and Technology, Vol. 33, No. 1, 149-156, doi:10.1007/s12206-018-1215-4 